\title{
The Role of Emotional Wisdom in Salespersons' Relationships with Colleagues and Customers
}

\author{
Richard P. Bagozzi \\ University of Michigan \\ Frank Belschak \\ University of Amsterdam, The Netherlands \\ Willem Verbeke \\ Erasmus University, The Netherlands
}

\begin{abstract}
Emotional wisdom is defined as a set of seven dimensions of basic skills and meta-narratives concerning how to regulate emotions within specific domains in such a way that the individual's and firm's well-being are tied together. Using operationalizations of emotional wisdom for salespersons from a wide range of industries (Study 1) and in automotive dealerships (Study 2), with respect to both colleagues and customers, it is discovered that salespeople who score high on emotional wisdom cope differently with socially challenging situations and achieve better social relationships than those who score low on emotional wisdom. @ 2010 Wiley Periodicals, Inc.
\end{abstract}

Suppose a salesperson compares him/herself with a colleague who is performing better than him/herself and feels envy as a result. S/he may regulate or control this envy by congratulating the colleague, so as to be able to maintain a good relationship with the colleague. Or imagine a salesperson who develops 
friendships with customers, yet has to present the firm in a professional manner when dealing with customers and avoid making inappropriate disclosures of private feelings. Researchers note that the ability to regulate one's emotions is an important part of work, especially for customer-boundary spanners, where ambivalent situations often occur such as described above (e.g., Fineman, 2000; Rafaeli \& Sutton, 1987; Morris \& Feldman, 1996).

Two general approaches exist for regulating one's emotions. First, one can regulate one's emotions in a goal-directed way so as to maximize one's self-interests and achieve one's individual goals. Second, a person can regulate his/her emotions such that self-interest as well as others' interests are balanced. The first approach reflects emotional intelligence (EI), whereas the latter is driven by emotional wisdom (EW) (Sternberg, Lautrey, \& Lubart, 2003; Kunzman \& Baltes, 2003). Although EI has attracted a lot of attention in the organization literature, EW has not. Neither has been studied to date in marketing.

EI, the capacity to regulate one's emotions, is frequently used to explain successful engagement in social interactions (e.g., Mayer, Salovey, \& Caruso, 2000; Salovey \& Pizarro, 2003). However, the concept of EI suffers from a number of weaknesses. (Goleman, 1998; Cherniss \& Goleman, 2001) notes that EI is too narrowly defined to carry great weight for management theory. First, EI fails to explain and predict concrete behaviors in specific domains (e.g., Cherniss \& Goleman, 2001); second, EI does not capture well people's balancing of their individual emotions with respect to requisites stemming from their organizational embeddedness (Saarni, 1999, 2000). Finally, and perhaps most importantly, putting too strong an emphasis on EI can lead to problems, because unfortunately individuals very high in EI exhibit such negative characteristics as ruthlessness and selfishness (Kunzman \& Baltes, 2003), thereby potentially damaging relationships in the firm or with customers. Somewhat similar criticisms have been made with regard to classic representations of intelligence (IQ, one's ability to fluently utilize one's intellectual capacities): "Some very intelligent people often use their intelligence to some very questionable ends" (Sternberg, Lautrey, \& Lubart, 2003, p. 18). As a consequence, the concept of wisdom has recently been introduced to refer to the capacity to orient one's cognitive resources (e.g., those captured by IQ and EI) toward meaningful individual ends and common goals (e.g., Kunzman \& Baltes, 2003). In an analoguous way, the concept of emotional wisdom is introduced to refer to emotion regulation that encompasses both selfinterest and the interests of the firm and customers. In this sense, it should be associated with a customer orientation as opposed to a sales or selling orientation and may also relate to empathy (Bagozzi et al., 2010).

People higher in emotional wisdom take into consideration the fact that conflicting norms on emotion regulation may emerge within specific domains (for instance, "Shall I show my true emotions to the customer or display prescribed ones to convey a particular impression?"). People skilled in emotional wisdom can accomplish this task by applying norms of "bounded emotionality" in their emotion regulation (e.g., Mumby \& Putnam, 1992, pp. 474-475), that is, combining individualization with relatedness and choosing appropriate actions based on a system of tolerance and ambiguity. The emotionally wise individual comes to realize that contradictions are inherent in social situations that need to be minded, and not repressed nor excessively ruminated about (see also Lewicki, McAllister, \& Bies, 1998). To get back to our example above: As salespeople develop friendships with customers, the relationships might evolve and 
contribute to feelings of ambivalence or divided loyalties. Emotional wisdom enables individuals to be mindful of these contradictions and integrate them, and it even leads to an appreciation of the value of inconsistencies (e.g., "I am not showing the emotions I actually experience but feel authentic and true to company goals nevertheless"). In this regard, emotional wisdom removes the need to solve contradictions (and cope with potentially resulting ruminations or feelings of guilt), thus preserving precious resources for the individual that might be used instead for different actions like coping or other goal-directed behaviors (Harter, 2002; Huy, 2002). Saarni (1999) speculates that the ability to integrate contradictory emotional skills provides the basis for personal satisfaction and a self-image of accomplishment.

Wisdom, as Brown and Starkey (2000) note, is an under-researched topic (cf., Bigelow, 1992; Waters, 1980; Weick, 1993). Emotional wisdom can be considered a special case of the new stream of research on positive psychology (see Seligman \& Csikszentmihalyi, 2000, p. 5, who explicitly mention wisdom) and on positive organizational behavior because it constitutes a positively oriented human resource strength and psychological capability which can be applied to and studied in today's workplace (Luthans, 2003, p. 179).

This article is organized as follows. First, the concept of emotional wisdom is developed and used to introduce seven domain-specific dimensions, which are then operationalized and tested in two studies for salespersons operating in positions with regular customer contacts. In Study 1, the explanatory value of EW is first compared to that of EI. Next, a configural approach to EW is used and clusters of wise emotion regulation are applied to salespersons in interactions with colleagues. In Study 2, configurations of EW are investigated for salespersons in interactions with customers. The relationships between EW, defined by clusters of scores on measures of the seven dimensions developed below, and coping, as well as quality of interpersonal relationships, are tested. The results confirm the explanatory value of $\mathrm{EW}$ in the sales setting.

\section{EMOTIONAL WISDOM AS THE ABILITY TO BALANCE MULTIPLE INTERESTS}

Within firms, salespeople are responsible for their actions, including the selfregulation of their emotions in specified roles. But regulating one's emotions such that both the self and the social environment thrive requires the explicit integration of one's personal beliefs concerning how one should regulate and express one's emotions in particular situations into the functioning of the organization. The goal of emotion self-regulation ought to be to encompass both the social environment (firm, customer) and the self in a coordinated way. A deemphasis of the self could result in emotional dissonance and negatively affect personal well-being as well as performance (e.g., Hochschild, 1983; Mumby \& Putnam, 1992; Morris \& Feldman, 1996). Likewise, neglect of the social environment could result in social isolation and alienation for the salesperson. The effortful willingness to consider and integrate self and social environment then becomes a project that when done purposively and well contributes to EW (e.g., Emmons, 1999; Brown \& Starkey, 2000).

Within the literature on intelligence, wisdom reflects the application of (tacit) knowledge as mediated by values toward the goal of achieving a common good 
through balancing multiple intrapersonal (self-interest), interpersonal (other people's interests), and extra-personal interests (contextual, e.g., the firm's interests) (Sternberg, 1998). As a result, people use their cognitive-emotional resources in a meaningful way that allows them to make informed and balanced decisions such that the self and social environment benefit (Kunzman \& Baltes, 2003). Whereas IQ has traditionally been measured using structured problems, such as speed of reactions to logical puzzles, wisdom deals with life problems that are complex, uncertain, difficult, and existential, thus posing difficulties of measurement. Wisdom consists of basic skills, such as in-depth knowledge about a social situation, and of meta-knowledge, that is, how one can deal with one's situation effectively. The former component encompasses factual and procedural knowledge (e.g., knowledge about what it means to operate successfully in one's firm), the latter implicit knowledge reflected in such implicit ideas as life-span contextualization (i.e., considering the many themes and contexts of life, e.g., "I will not express direct value judgments that hurt the firm and my career") and value relativism (i.e., acknowledging and tolerating value differences, e.g., "I need to balance the interests of the firm and my colleagues") (Staudinger \& Baltes, 1996; Sternberg, 1998). Emerging research suggests that wisdom has to be achieved within each particular domain, and is thus domain-specific (Staudinger \& Baltes, 1996), it is learned largely on one's own (Sternberg, 1998), and, most importantly, people with higher levels of wisdom attempt to engage in actions where both the self and the other benefit (Kunzmann \& Baltes, 2003).

It is proposed that the dimensions of emotional wisdom similarly can be grouped into two categories. First, there are basic emotional skills (e.g., empathy or perspective taking - taking the point of view of others-which allows people to better sense and appraise their social environment). Second, meta-narratives reflect a set of implicit ideas on how to regulate one's emotions. For example, when and how much a salesperson prefers to engage in face work, when to appeal to one's norms when dealing with one's emotions, and when and to whom to disclose one's private emotions are reflected in personal meta-narratives. Emotional wisdom is associated as well with an ability to put one's emotion regulation into a broader perspective (Bigelow, 1992), and it involves a shift in selfperception from "self as independent person" to "self as part of a larger whole" (Bigelow, 1992, p. 147).

\section{EMOTIONAL WISDOM AS DOMAIN SPECIFIC AND MULTIDIMENSIONAL}

Seven dimensions are introduced that, while not necessarily exhaustive, capture much of research in both the literature on EW and the literature on psychological development and coping and reflect how salespeople interact with colleagues and customers in their role set. Applying the concept of wisdom to the notion of emotions, as explained above, it is found that Saarni's $(1999,2000)$ concept of emotional competence (i.e., the regulation of one's emotions in socially and morally acceptable ways) helps break the abstract definition of EW down into concrete proficiencies. These proficiencies are applied to the domain of personal selling by bringing them to terms with the literature on emotion regulation in organizations and emotional work (e.g., Ashforth \& Tomiuk, 2000; Huy, 2002; Mumby \& Putnam, 1992). Moreover, the proficiencies can be generalized and 
applied to all employees who interact with customers on a regular basis, such as service people and account managers. The dimensions developed below are the result of this theoretical process and might be considered prerequisites for being able to show EW. The first two dimensions are conceived as basic emotional skills, and the five remaining dimensions are conceived as meta-narratives. Typically, the skills exist and have to be achieved separately for different domains. For instance, it is possible that a salesperson might apply EW well in front of the customer but not with his/her colleagues (or vice versa).

\section{Basic Emotional Skills}

1. Empathy is defined as the ability to apprehend or comprehend the emotional state of another person and to experience a similar affective response oneself (Eisenberg, 2000, p. 677; Saarni, 1999, p. 165). Recent research shows that empathy is learned to a large extent (Preston \& de Waal, 2002). Salespersons with greater empathy are better listeners; they also sense the feelings of others better, and this provides the basis for more social influence and allows them to discern when it is appropriate or not to use their emotions instrumentally (Ashforth \& Humphrey, 1993).

2. Dissociation of guilt from strategic intent: Skills in the strategic regulation of emotions may come to naught if the communicator counterfactually anticipates self-guilt in their use. Rafaeli and Sutton (1987, p. 32) speak in this regard about a "person-role conflict, or a clash between personal values and role requirements." In one study, hairdressers who felt pleased and proud about their ability to get customers to talk about themselves actually produced more satisfying interactions, while those who felt guilty about their ability to get customers to talk about themselves produced less satisfying interactions (Parkinson, 1991).

\section{Meta-Narratives}

3. Instrumental use of emotions (self-presentation): Everyday interactions in organizations contain extensive opportunities for acting out emotional repertoires (cf. Rafaeli \& Sutton, 1987; Morris \& Feldman, 1996). If salespersons show appropriate emotions in their role interactions (e.g., Sutton, 1991), this will increase the chances that emotional contagion will occur (Barsade, 2002). This requires that salespeople strategically inhibit, attenuate, or amplify appropriate emotional expressions seemingly spontaneously (a process termed emotional dissembling; Saarni, 1999). The instrumental use of emotions can be scripted to a certain extent, and firms take advantage of this property by training employees how to use "feeling rules" (e.g., Sutton, 1991).

4. Helping others accept one's emotions: Whereas the display of genuine emotions requires relatively little effort (Leary \& Kowalski, 1990), considerable control is needed to create or show emotions that differ from those actually felt. Therefore, it is sometimes a better strategy to attempt to help others accept one's emotions instead of trying to change or dissemble them per se (Saarni, 1999). Emotionally wise employees thus not only need the ability to dissemble their emotions or use them strategically but 
also in a sense to "impose" their genuine emotions on others and make them feel comfortable in the process (see Goleman, 1998; Cherniss \& Goleman, 2001).

5. Feelings of authenticity: Erickson (1997) notes that we live in a "therapeutic emotional culture," where the process of emotion regulation is considered normal, an assumption that seems to be particularly appropriate during customer contact, when salespeople attempt to create a meaningful experience for customers (e.g., Rafaeli \& Sutton, 1987; Morris \& Feldman, 1996). Yet, under this conception, emotion regulation functions in ways that are consistent with well-being and authenticity. In this regard, feelings of authenticity are opposite to feelings of emotional dissonance: Salespeople feel authentic when they feel comfortable with the way they express their emotions (see also Hochschild's, 1983, study of flight attendants).

6. An ironic outlook: Hatch (1997, p. 281) suggests that irony is achieved through the willingness to let go of conventional ways of viewing experience, and to try on new vocabularies and interpretive routines. Irony serves as a mechanism for tolerating emotionally ambiguous situations and applying contradictory coping strategies (e.g., Hatch, 1997; Huy, 2002). Similar to humor, irony produces dissociation from negative feelings (Keltner, 1995; Dixon, 1980). Since irony can accommodate contradictory emotional and mental states, it can support contradictory realities for individuals; for instance, salespeople who are expected to act assertive and customeroriented at the same time might benefit from an ironic outlook.

7. Character, that is, applying personal moral norms: When dealing with one's own emotions with customers or colleagues, emotionally wise salespersons have to act in accordance with company norms as well as their own moral norms. Emotion regulation therefore can come to be deeply influenced by a person's moral norms and ethical values in ways that promote personal integrity (Saarni, 2000, p. 69). Such moral norms may well reflect the Aristotelian virtues for instance. The possession and application of personal moral norms (1) helps salespeople keep their emotion regulation within limits with which they feel comfortable; (2) inhibits too selfish and individualistic behaviors; and (3) makes their future behavior more predictable for others (Saarni, 1999). Organizational behavior researchers also conclude that the maintenance of standards of honesty and integrity promotes trustworthiness (e.g., Goleman, 1998; Mayer, Davis, \& Schoorman, 1995), and they acknowledge the importance of "a sense of honesty, fairness, justice, and respect" for fostering change processes within companies (Huy, 1999 , p. 335). Researchers in marketing note that the maintenance of standards of honesty and integrity promotes trustworthiness in business relationships (Crosby, Evans, \& Cowles, 1990; Morgan \& Hunt, 1994).

\section{STUDY 1: EMOTIONAL WISDOM WITHIN THE COMPANY}

\section{Emotional Wisdom and Emotional Intelligence}

The concept of EW is introduced and it is argued that it is preferable to the more limited concept of EI for establishing social relationships. In what follows, 
it is proposed that EW explains unique variance in relationship quality beyond that explained by EI. Researchers note that trust is important for the development of a good interpersonal relationship and cooperation within firms (e.g., McAllister, 1995). Colleagues' trust, however, is centered on the question of whether an employee is mainly driven by self-interest or also considers others' interests (e.g., Clark \& Mills, 1979; Clark, Mills, \& Powell, 1986; Holmes \& Rempel, 1989). Taking others' welfare into consideration and finding a balance between self-interests and other people's interests is a defining characteristic of wisdom, and is especially relevant to the sales context, where salespersons interact with colleagures and customers on a regular basis. Emotionally intelligent people, on the other hand, tend to strive for maximization of self-interests, and do so at times at the cost of other people's interests (Barrett \& Gross, 2001; Kunzman \& Baltes, 2003). In this respect, one can expect that emotionally wise salespeople will be able to evoke higher levels of trust and, in turn, better relationships and cooperation with colleagues than those who are "merely" emotionally intelligent.

In addition, recent research on social relationships finds that employees often experience trust and distrust at the same time (Lewicki, McAllister, \& Bies, 1998): Over time, within the same relationship, parties will have different encounters with different intentions that lead to different outcomes, which sometimes foster trust and sometimes distrust. In this respect, ambivalence is commonplace within organizations, and especially selling situations, where organization boundaries are spanned. Psychologists argue that such psychological imbalance is an aversive condition that social actors seek to resolve (e.g., Blau, 1964; Deutsch, 1968; Festinger, 1957). This may lead to problems: On the one hand, people might ignore negative information and completely trust their colleagues. As a consequence, they might overrate the quality of their relationship with a colleague and invest more in it than the outcomes might justify. Or people might ignore positive information and distrust their colleagues. This may lead to underrating of relationship quality and, in turn, to premature abandoning of relationships. In either case, employees will not be able to establish good relationships with their colleagues. Emotionally wise people, however, are distinctively characterized by their ability to handle emotional ambivalences and conflicts. They can therefore realistically take a wide scope of relevant information into account and achieve better relationships and cooperation than less emotionally wise people (Lewicki, McAllister, \& Bies, 1998). Hence it is hypothesized:

H1: Emotional wisdom explains unique variance in relationship quality beyond that explained by emotional intelligence.

\section{Configurations of Emotional Wisdom within the Company}

The aim is to empirically identify configurations of emotionally wise salespeople (i.e., those who are able to integrate all of the proficiencies of emotional wisdom) and distinguish highly emotionally wise salespeople from those lower in EW. Those employees who have not incorporated one or more of the seven dimensions of wisdom as part of their emotion regulation are defined as being relatively low on EW. In line with configurational thinking (e.g., Farmer \& Maslyn, 1999; Meyer, Tsui, \& Hinings, 1993), it is maintained that a lack on one of the dimensions of emotional wisdom tends to create a negative spiral on other 
dimensions of EW, thus creating specific configurations differentiating salespersons from each other. The ways the different dimensions of $\mathrm{EW}$ cohere in specific configurations provide insights into the mechanisms that give rise to lower EW, thus explaining why the proficiencies of EW covary in specific manners. Such a research approach is grounded in the notion that "the parts of a social entity take their meaning from the whole and cannot be understood in isolation" (Meyer, Tsui, \& Hinings, 1993, p. 1178). For instance, low empathetic people are known to develop guilt because they anticipate the psychological discomfort that colleagues have when finding out that they were only acting (Zahn-Waxler \& Robinson, 1995). To the extent that they experience difficulty in dissociating guilt from the episode, salespeople may develop feelings of inauthenticity, and this might affect their performance negatively. Below, five different ways are considered that salespeople might integrate the dimensions of $\mathrm{EW}$ that are manifest theoretically in the organizational behavior and the psychology literatures.

1. Salespeople highest in EW (see Sternberg, 1998; Saarni, 1999) should score high on all seven dimensions. Such an organization of wisdom dimensions serves to maximize salespersons' self-interests with the interests of others and the firm (see Sternberg, 1998; Baltes \& Staudinger, 2000). Some salespeople have been found to be able to simulate a wide range of emotions during customer contacts and yet continue to feel authentic, as their emotional acting fits in with their moral norms. As a consequence, they do not develop feelings of guilt about the way they handle their emotions. This has been called "faking in good faith" (Rafaeli \& Sutton, 1987). In line with Erikson's (1968) observation that only a small number of people achieve a high level of emotional control, it is expected also to find multiple configurations of low EW for employees, such that people score low on one or more of the seven dimensions.

2. The literature on configurations of individual differences suggests that a group of people may consistently score low on many or even all dimensions (e.g., Kipnis \& Schmidt, 1988). With respect to EW, the main trigger for overall low scores might be salespersons' deficits of empathy, which inhibit their ability to appropriately regulate their emotions instrumentally and in turn makes them feel inauthentic. Consequently, they lack the efficacy to make others accept their emotions, let alone to develop an ironic perspective about their own dissonant feelings. Such a group might be akin to Rafaeli and Sutton's (1987) “deviant employees," who expressed their inner feelings and disregarded display rules, yet felt guilty about it because such behavior clashes with internalized role expectations.

3. It is further expected that one or more groups of salespeople will score high on some dimensions yet low on other key dimensions. First, consistent with the notion of EI (e.g., Goleman, 1998; Mayer, Salovey, \& Caruso, 2000), it is reasonable to expect a group of salespersons who have high scores on empathy and are flexibly able to either show their emotions strategically or convince others to accept their emotions, depending on the situation. As noted in the literature (e.g., Barrett \& Gross, 2001; Huy, 1999), emotionally intelligent people tend not to feel guilty about such emotional work, because they regulate their emotions to their own 
advantage and do not hold strong moral norms against doing so. These characteristics also relate to Machiavellianism (Christie \& Geiss, 1970), a current theme in the organization literature that attributes somewhat similar configurations of emotion regulation activities to people who tend to use people to achieve their own ends.

4. Consistent with the program of research in the organization literature on emotional work/labor, it is reasonable to expect a group of salespeople who are able to express emotions strategically, yet experience feelings of inauthenticity when doing so. This phenomenon is similar to emotional dissonance (e.g., Hochschild, 1983; Rafaeli \& Sutton, 1987; Ashforth \& Tomiuk, 2000). Rafaeli and Sutton (1987), as well as Parkinson (1991), argue that feelings of guilt emerge when people express emotions they do not actually feel. That is, this group of salespeople should be able to use their emotions instrumentally, yet feel inauthentic in doing so and develop guilt as a consequence. To compensate for this lack of person-job fit, thus allowing them to continue in their work and not quit their jobs, they have to draw on such resources as an ironic outlook, which is known to act as a resource for coping with stressful events (e.g., Keltner \& Bonanno, 1997).

5. Finally, in line with recent research on positive psychology (e.g., Fredrickson, 2001; Luthans, 2002; Seligman \& Csikszentmihalyi, 2000), it is reasonable to expect a group of salespeople who possess most of the capabilities of emotionally wise people, yet are not capable of developing an ironic perspective on themselves. Laughter functions as a transient, mild form of dissociation from distress that leads to joy and a sense of peace (Keltner \& Bonanno, 1997; Dixon, 1980); consequently, salespeople lacking in the ability to experience irony are unable to let go of feelings of contradiction that might come with emotional work. This notion has been elaborated upon by Hatch (1997; see also Westwood, 2004), who notes that ironic humor provides a means for exploring and integrating contradictory issues. In this regard, irony plays a fundamental role in EW, allowing people to accept and integrate contradictions. Salespersons lacking the means to integrate contradictory proficiencies (such as using one's emotions instrumentally, yet feeling authentic rather than guilty about it) should find it difficult to achieve high levels on the other dimensions of EW. Therefore,

H2: Salespeople will differ in emotional wisdom such that the pattern of responses to measures of the seven proficiencies will yield one group of people who score high on all dimensions and multiple groups of people who score low on one or more dimensions.

The first group we term the group high in emotional wisdom, the latter groups the groups low in emotional wisdom.

\section{Validation of the Configurations in an Intra-Organizational Setting}

To validate the configurations of EW derived in our research (see below), we investigated the interactions between sets of individual attributes (the configurations of $\mathrm{EW}$ ) and outcomes (coping and relationship quality) in the general 
expectation that the emotionally wise salespeople will achieve more superior outcomes than the less wise salespeople. In doing this, we focus on the patterns of influence that characterize each individual rather than those that characterize the differences between individuals (see Farmer \& Maslyn, 1999; Meyer, Tsui, \& Hinings, 1993).

Emotional Wisdom and Coping with Envy. Below, an exploration is done into how different groups of emotionally wise salespeople self-regulate their emotions during socially challenging moments, namely the experience of emotional envy, which is a common experience among salespeople in the same firm. Envious salespeople risk getting so consumed with their envy that they engage in gossip, fail to help others when needed, and even react in destructive ways (e.g., East \& Watts, 1999). Thus, the challenge for salespeople is to regulate their envy in adaptive ways and avoid the negative consequences.

Based on recent research on coping (see Campos, 1994; Folkman \& Lazarus, 1988; Saarni, 1997, 1999), two general coping strategies are proposed that are difficult to achieve in combination. The first coping strategy relates to managing the experience of an emotion in such a way that the salesperson can profit from it (e.g., seeing it as a call to work harder). The second strategy is about managing the expression of an emotion so as to avoid negative social consequences (e.g., congratulating colleagues for their performance despite feeling envious). As for envy, the salesperson might perceive it as a "wakeup call" to work harder and perform better, but without being destructive to others. Yet managing both the experience and expression of one's emotions takes effort, particularly if these coping activities are felt to be in contradiction to the actual emotional experience (Leary \& Kowalski, 1990).

Emotionally wise salespeople should be better at affect control because they are able to accept ambiguities and contradictions in their environment and hence are more at ease with their situation (such as "I feel an emotion" and "I have to work on my emotions") (see Pascual-Leone, 1990) and therefore possess more cognitive and emotional resources that allow them to cope better with their envy. Second, emotionally wise salespeople are also better able to integrate the contradictions between their experience of envy ("I feel envious") and their coping activities (e.g., "I must not show that I am envious"). Third, emotionally wise salespeople take responsibility for their coping, such that they are mindful of individual interests (perceiving the felt emotion as a wakeup call to work harder and perform better) and social interests (not being destructive to others). In other words, emotionally wise salespeople are more resilient (Saarni, 1999). Thus,

H3: Emotionally wise salespeople regulate the experience and the expression of felt envy more than less emotionally wise salespeople.

Emotional Wisdom and Relationships with Colleagues. Recent research shows that salespeople provide added value to customers when they cooperate with and obtain information from colleagues (e.g., Weitz \& Bradford, 1999; Seibert, Kraimer, \& Liden, 2001). Colleagues constantly evaluate each other in terms of how well they handle their emotions and to what extent they take themselves and the organization into consideration when regulating emotions. Emotionally wise salespeople feel more embedded within their social 
environment and have a greater preference for cooperation rather than withdrawal, dominance, or conflict (e.g., Kunzmann \& Baltes, 2003, p. 339). This attitude and related actions create feelings of trust among colleagues (e.g., McAllister, 1995), because emotionally wise salespeople take personal as well as social interest into consideration (rather than one at the expense of the other) and strive for joint flourishing. This can be seen as a currency that causes people to reciprocate, leading them in return to share information-ranging from common details to more strategic information (Adler \& Kwon, 2002). Similarly, researchers note that a person's trust in another person is not only a reaction to what a person does but also to the perceived reasons for their acts, particularly the evaluation of that person (Hardin, 2003; Morgan \& Hunt, 1994). Emotionally wise salespeople will raise more favorable appraisals in this regard and hence receive more from others (e.g., colleagues) because they strive for joint prospering. Therefore,

H4: Emotionally wise salespeople will achieve relationships of higher quality than less emotionally wise salespeople.

\section{ORGANIZATIONAL CONTEXT}

\section{The Sales Profession}

Salespeople work as customer boundary spanners in firms, similar to, for instance, service people. As such, they are responsible for maintaining good relationships with customers, and they act as representatives of their firm. Within the group of boundary spanners, salespeople are distinct from others as they have an additional obligation besides maintaining good relationships with their customers: They also have to make deals, which is explicitly mentioned in their job description. Salespeople experience a strong pressure to sell successfully because they are, to a large extent, compensated on the basis of bonuses or commissions. In this respect, they are in an ambivalent position: On the one hand, they ought to maintain good relationships with their customers; on the other hand, they also ought to be assertive and convince their customers to buy their products, and the one role may easily come at the expense of the other.

\section{Sales in the Netherlands}

The salespeople studied herein worked throughout the Netherlands. Personal selling positions in the Netherlands are mainly occupied by men, despite the reputation of the Netherlands as a society based on open-mindedness and egalitarianism. It turns out that, historically, personal selling is perceived as an occupation low in prestige in the Netherlands, and most salespeople see it as a stepping stone for another career, for instance in marketing. Salespeople in the Netherlands frequently attend continuing education courses, in which they are trained in communications skills with customers, as well as selling techniques: They are taught to be instrumental and goal-oriented in their communication and behavior toward customers. In addition, Dutch salespeople are not paid very well compared to salespeople in other European countries or the U.S. Finally, the average educational level of Dutch salespeople is significantly lower than 
for employees working in such areas as general marketing, human resource management, or accounting, with relatively few individuals having attended university.

\section{The Setting of Study 1}

Twenty companies were contacted from a variety of industries ranging from insurance to pharmaceutical products, asking them to participate in a study on emotional intelligence. These salespeople mostly visited their customers personally, and maintaining personal relationships with their customers was an important part of their business. They spend much time traveling by car and visit four to five customers per day on average. Customers, here, were mainly firms. The salespeople had a large degree of autonomy, as they had little specific directives by their supervisors on how to plan or carry out their work.

\section{The Setting of Study 2}

Here questionnaires were sent to salespeople who worked for two large automotive dealers in the Netherlands with dealerships spread over the whole country. Although these salespeople sold cars, they are, similar to respondents in Study 1, characterized by high levels of autonomy on how to conduct their sales job. Particularly for business customers, a visit to the car dealer is only the first step toward a deal, and few deals are actually closed at that time. Salespeople therefore have to maintain their customer relationships and seek to make the re-buy decision. The salespeople in this study sold equally to final consumers and companies, such as taxi firms.

\section{STUDY 1 METHOD}

\section{Sample}

A total of 20 companies agreed to participate in our study. We sent 415 questionnaires to salespeople in these companies. Two hundred five salespeople returned the questionnaires for a $49 \%$ response rate. As an acknowledgment of their participation, respondents received a 1-euro coin (about 1 U.S. dollar) as a gift. The sample can be described as follows: A majority (81\%) of the salespeople were men, $25 \%$ of the salespeople were 30 years old and younger, $50 \%$ were between 30 and 40, 20\% between 41 and 50, and 5\% were older than 50 . On average, the account managers had 5.6 years experience working in their firms ( $S D=6.8$ ), and $75 \%$ had finished basic and advanced vocational studies, while $25 \%$ had a university degree.

\section{Measures}

Emotional Wisdom. A 23-item scale was developed to capture the seven proficiencies that constitute EW as outlined above (see Appendix). Where possible, the development of the items was based on the adoption of existing scales from the psychology literature to a marketing sales setting with colleagues. 
Where no well-validated scales existed for measuring the proficiency in question, item development was based on Saarni's (1999) description of emotional competence, research on emotional work (in particular, Ashforth \& Tomiuk, 2000; Ashforth \& Humphrey, 1993; Parkinson, 1991), and in-depth interviews with salespeople in a focus group. Four items (e.g., "I can easily put myself in the place of my colleagues and their needs") refer to one's capacity for empathetic involvement with others' emotional experiences. The formulation of the items was based on the emotional empathy scale by Mehrabian and Epstein (1970). Two items (e.g., "I feel little guilt when showing my enthusiasm during a conversation with colleagues") reflect the expectation that emotionally wise people will experience low levels of guilt about the way they work on their emotions. Two additional items capture people's tendencies to express their true feelings within particular situations (authenticity) (e.g., "My expressed emotions are part of what I see as my truthful way of dealing with people"); creation of these items was based on Averill's (1999) scale on authenticity. Based on Wong and Law's (2002) scale of deliberate emotion regulation, another four items were developed to measure salespeople's ability to instrumentally use their emotions (e.g., "I am knowledgeable about how to create emotions to facilitate the way sales interactions operate"). Three additional items were derived to measure the ability of the salesperson to help others to accept his / her emotions (e.g., "Others have learned to accept the way I regulate my emotions"). Next, the degree to which a person uses an ironic outlook was measured by four items (e.g., "I can easily laugh about myself when my emotions get carried away"). The final four items of the scale capture how a person's character relates to emotional selfregulation (e.g., "I have certain norms about the way I regulate my emotions"). The Appendix also presents the factor loadings for items and reliability coefficients for subscales.

Coping with Envy. This scale was constructed with six items with responses coded on 7-point Likert scales and reflects the two general coping strategies for managing one's emotional experience and managing one's emotional expression in the literature (see Campos, 1994; Folkman \& Lazarus, 1988; Saarni, 1997, 1999). Three items captured salespeople's actions to regulate the expression of their envy (e.g., "I do not put the performances of my colleagues down," $\alpha=$ 0.75). Another three items measured the degree to which they regulated the experience of their envy (e.g., "I immediately think that I could also achieve this performance, if I worked so hard," $\alpha=0.86$ ).

Relationship Quality. The items for this scale were generated based on research on relationships between colleagues (e.g., Adler \& Kwon, 2002; in particular, Nahapiet \& Ghoshal, 1998) and on account management effectiveness (Workman, Homburg, \& Jensen, 2003). The scale consists of nine 7-point Likert scale items reflecting salespeople's ability to mobilize resources from their colleagues. The items cover a range of different important aspects of effective collaboration within an organizational environment mentioned in the literature (Nahapiet \& Ghoshal, 1998; Homburg, Workman, \& Jensen, 2002; Workman, Homburg, \& Jensen, 2003), such as an employee's ability to get additional information about his/her own organization (e.g., "Almost everybody shares information with me about important topics in our organization"), to achieve strategic information (e.g., "I make sure that I attain the strategic information 
from my colleagues"), and to obtain information quickly, as well as a salesperson's abilities to connect with people (e.g., "I can get the better people in my organization around me to get projects done"). The reliability of the scale is $\alpha=0.85$.

Emotional Intelligence. As a measure of EI, the authors used the scale developed by Schutte et al. (1998), which is based on a conceptual model proposed by Salovey and Mayer (1990). The scale consists of 26 items (e.g., "I am aware of my emotions as I experience them"). The reliability of the scale is $\alpha=0.90$.

\section{Confirmatory Factor Analysis (CFA)}

To assess convergent and discriminant validities of the scales, a CFA was conducted for the different factors of EW, relationship quality, coping with envy, and EI. Satisfactory model fits are indicated by nonsignificant chi-square tests, RMSEA values less than 0.08, and CFI values greater than or equal to 0.90 . Discussions of indices can be found in Bentler (1990) and Browne and Cudeck (1993). Results of the CFA validated the structure of the above scales: $\chi^{2}(657)=$ $933.74(p=0.00), \mathrm{CFI}=0.90$, and RMSEA $=0.05$. Factor loadings were moderately to very high for all factors: empathy (0.59 to 0.77$)$, guilt (0.52 to 0.78 ), authenticity ( 0.72 to 0.81 ), self-presentation ( 0.67 to 0.80$)$, helping others to accept one's emotions ( 0.56 to 0.76 ), irony ( 0.62 to 0.70$)$, character ( 0.45 to 0.71 ), social capital ( 0.45 to 0.79$)$, managing expression of envy ( 0.50 to 0.85$)$, and managing experience of envy ( 0.80 to 0.84 ). The measures of discriminant validity, based on correlations among factors and their standard errors, reveal that the factors are distinct.

To test for common method biases (such as self-serving bias or social desirability), a CFA was run with a same-source first-order factor added. This extra factor was defined as having as indicators all the self-report measures (see Podsakoff \& Organ, 1986; Podsakoff et al., 2003). Such a procedure has the effect of controlling for that portion of variance that is attributable to obtaining all measures from a single source. Factor loadings after correction for common method variance were as follows: empathy ( 0.48 to 0.61$)$, guilt $(0.49$ to 0.63$)$, authenticity (0.53 to 0.87 ), self-presentation ( 0.57 to 0.76 ), helping others to accept one's emotions ( 0.48 to 0.67$)$, irony $(0.57$ to 0.66$)$, character $(0.45$ to 0.78$)$, social capital $(0.42$ to 0.79$)$, managing expression of envy ( 0.41 to 0.75$)$, and managing experience of envy ( 0.76 to 0.81 ). Inter-factor correlations ranged from -0.26 to 0.62 . Partialing out the effects of common method variance hence did not have a substantial impact and thus there appears to be a low amount of common method bias.

\section{STUDY 1 RESULTS}

\section{Emotional Wisdom and Emotional Intelligence}

To investigate discriminate validity of the measures of wise emotion deployment as compared to EI, a hierarchical regression analysis was conducted, including EI and EW. In a first step, the relationship quality scale was regressed on a number of control variables, namely age, gender, education, organizational tenure, and sales experience. Next, the EI scale was added to the analysis, resulting in an additional 27 percent of explained variance $(F$-change $=72.18$, 
$p<0.000$ ). In a final step, EW was included in the regression. The wisdom scale explained an additional 11 percent of the variance of relationship quality $(F$-change $=34.17, p<0.000)$. Only EI and EW had a significant effect on relationship quality $\left[F(7,178)=20.45, p<0.000, R^{2}=0.43\right]$. H1, therefore, receives substantial support.

\section{Cluster Analysis}

The cluster analysis and its validation follow the split-sample validation approach suggested by Singh (1990). The data were randomly split into an analysis sample $\left(N_{a}=108\right)$ and a validation sample $\left(N_{v}=97\right)$. The analysis sample was first used to find possible cluster solutions. As the different dimensions of emotional competence were not expected to be nested in each other, yet non-hierarchical cluster analysis is sensitive to the required a priori specifications of the number of clusters to be extracted, as well as their centroids (Punj \& Stewart, 1983), a combination of hierarchical and non-hierarchical analysis was used. A hierarchical cluster analysis with the seven factors of EW was performed initially, suggesting a plausible range of three to six meaningful clusters. These plausible clusters and their centroid estimates were used in a subsequent $K$-means cluster analysis. Next, using the validation sample, we entered cluster centers for each of the plausible solutions obtained from the analysis sample into a $K$-means cluster analysis. For all possible cluster numbers, a constrained and an unconstrained solution were computed, and the chance corrected coefficients of agreement of the constrained and the unconstrained cluster solutions (kappas) were computed to identify an optimum: A maximum kappa represents the solution with the maximum stability and reproducibility. The kappas for the 3-, 4-, 5 -, and 6 -cluster solutions were $0.85,0.80,0.87$, and 0.70 , respectively. The 4 -cluster solution was therefore proposed as the most internally valid combination of clusters; also, its kappa exceeds the critical 0.70 limit (e.g., Singh, 1990). Once the optimal cluster value was determined, the analysis and the validation samples were pooled again and input into a final $K$-means cluster analysis with the number of clusters specified as the optimal value to receive the centroids for the whole sample. The results of this final cluster analysis are displayed in Table 1. In what follows, the recognizability of the clusters will be discussed to verify whether they have meaningful interpretations (Rich, 1992).

High Emotionally Wise Salespeople. Cluster 1 represents individuals who show high emotional competence on all proficiencies. These salespeople perceive the emotions of their communication partners accurately, adapt their emotions to situational necessities (self-presentation), and remain authentic at the same time. Further, these salespeople are able to regulate their emotions by using irony and thereby distance themselves from their emotions. At the same time, they keep strong moral norms about how to regulate their emotions, and they do not feel guilty about working on their emotions. Finally, others accept their emotion regulation style. In sum and in line with the literature on wisdom (Sternberg, 1998, 2003) and emotional competence (Saarni, 1999, 2000), a group of emotionally wise salespeople was found that was able to integrate all seven proficiencies of EW. These salespeople were able to integrate the inherent contradictions of the seven proficiencies of EW (e.g., "use your emotions strategically but feel authentic"). 
Table 1. Results of the Cluster Analysis in Study 1.

\begin{tabular}{lcccrc}
\hline & $\begin{array}{c}\text { High } \\
\text { Emotional } \\
\text { Wisdom } \\
(n=75)\end{array}$ & $\begin{array}{c}\text { Emotionally } \\
\text { Incompetent } \\
(n=49)\end{array}$ & $\begin{array}{c}\text { Emotionally } \\
\text { Dissonant } \\
(n=23)\end{array}$ & $\begin{array}{c}\text { Low } \\
\text { Irony } \\
(n=27)\end{array}$ & $\begin{array}{c}\text { Emotionally } \\
\text { Unwilling } \\
(n=30)\end{array}$ \\
\hline Self-presentation & 1.07 & -0.44 & 0.08 & 0.75 & -1.45 \\
Empathy & 0.79 & -1.37 & 0.44 & 0.88 & -0.73 \\
Irony & 1.18 & -0.07 & 0.41 & -1.56 & 0.03 \\
Authenticity & 0.61 & -1.53 & -0.50 & 0.58 & 0.84 \\
Guilt dissociation & 0.68 & 0.15 & -1.74 & 0.66 & 0.25 \\
Helping others & 1.34 & -0.32 & -0.15 & 0.49 & -1.36 \\
Character & 0.82 & -1.14 & -0.57 & 0.25 & -0.36 \\
\hline
\end{tabular}

Note: Values in this table are $z$-standardized; that is, values of about zero indicate an average activity on this dimension.

Emotionally Incompetent Salespeople. Cluster 2 consists of salespeople with the lowest profile on emotional wisdom. They score lowest on three dimensions of the EW scale and second lowest on the remaining dimensions. The most striking result for these salespeople is their very strong feelings of not being authentic in their displayed emotions. At the same time, they also think that other people do not accept the way they regulate their emotions, and they are unable to distance themselves from their emotions by using an ironic outlook. Moreover, these salespeople characterize themselves as relatively lacking in moral norms or limits on the regulation of their emotions. One possible explanation for this group is that these salespeople lack the ability to empathize or may even be relatively alexithymic (Sifneos, 1973). Alexithymia is the inability to experience and express emotions (Haviland \& Reise, 1996) and, consistently, salespeople falling into this cluster suffer from a lack of empathy and are able neither to use their emotions strategically nor to explain and help others accept their (the salesperson's) genuine emotions.

Emotionally Dissonant Salespeople. Cluster 3 consists of salespeople who experience very strong feelings of guilt and relatively strong feelings of inauthenticity regarding the way they regulate and use their emotions. Even though they are relatively empathetic and able to use their emotions instrumentally toward colleagues, they do not apply moral norms well and are not able to help their colleagues well to accept their genuine emotions. These salespeople exhibit properties consistent with Hochschild's (1983) concept of emotional dissonance. This group of salespeople also scored relatively high on the EW dimension of ironic outlook, a finding consistent with the laughter-asdissociation hypothesis (Keltner \& Bonanno, 1997). Humor allows a person to let loose of his/her emotions through laughter. First, laughter involves shifts from negative to positive psychological states. Second, laughter produces a reduction in negative emotions associated with a certain situation. Finally, the reduction of negative emotions creates positive feelings of amusement. The result is some respite from needing to continuously work on one's emotions, which otherwise could - in the case of emotionally dissonant salespeople-lead to dissatisfaction, burnout, and even turnover. 
Low-Irony Salespeople. Cluster 4 consists of individuals who score above average on every dimension of emotional competence, except ironic outlook, where in fact they score the lowest by far. That is, they are moderately empathetic and not hampered by guilt, they are relatively able to instrumentally adapt their emotional display to the situation and yet be authentic, and they are moderately facile in helping others to accept their emotions. These salespeople also apply moral norms to their emotional work. But they are unable to distance themselves from and regulate their emotions through an ironic outlook. Based on recent research on humor (Hatch, 1997; Avolio, Howell, \& Sosik, 1999; Westwood, 2004), it can be concluded that the study of how humor interacts with other dimensions of EW can help one better understand how it functions. Lack of humor seems to corrupt the use of the other proficiencies of EW (see Farmer \& Maslyn, 1999). A lack of humor might inhibit one's ability to interpret and reconcile contradictory emotional experiences, and salespeople in the low-irony group risk being prisoners of their emotions. Hatch (1997, p. 285) notes in this context that "what is key here is that, with a little irony, we both can be conscious of these [contradictory emotional] processes and thereby bring them into clearer focus." By focusing on laughter and humor, as opposed to negative emotions, salespeople are apparently able to neutralize emotional denial of contradictory cognitions, which, in turn, can be confronted and integrated (Hatch, 1997).

Emotionally Unwilling Salespeople. Finally, cluster 5 consists of salespeople who are neither able to use their emotions instrumentally nor to convince their colleagues about their own emotions. Similarly, they are characterized by a lack of empathy. They do feel authentic about the way they handle their emotions and do not experience guilt. The properties of this group are consistent with people who are not able (or willing) to engage in emotional work toward their colleagues (see Ashforth \& Tomiuk, 2000; Morris \& Feldman, 1996). Similarly, they do not apply moral norms or standards to their emotional work. Finally, irony is not much of a factor for people in this cluster. Ashforth and Tomiuk (2000) identified a similar group of people in their study of service agents: They found that a considerable percentage of their respondents stated that they did not regulate their emotions actively but felt that their expressed emotions were authentic: "These respondents typically prided themselves on what they regarded as their honest and straightforward manner" (p. 188).

In sum, the results provide evidence for five categories of salespeople, one in which salespeople score the highest on all seven dimensions of EW and four in which salespeople score the lowest on at least one dimension of EW. H2 thus receives support.

\section{Validation: Results of MANCOVA}

The predictive validity of the clusters described above was explored by investigating their effect on relationship quality and coping responses to envy, where the latter is potentially a particularly socially disruptive emotion in such situations. A MANCOVA was run with coping and relationship quality as dependent variables and cluster membership as a multicategory independent treatment variable. Age, years of working experience, and level of education were included in the analysis as covariates. Since education was only measured on an ordinal level, the sample was split in two groups, namely high education (college or 
Table 2. Results of MANCOVA in Study 1.

\begin{tabular}{|c|c|c|c|c|c|c|}
\hline & $\begin{array}{l}\text { High } \\
\text { Emotional } \\
\text { Wisdom } \\
(1)\end{array}$ & $\begin{array}{l}\text { Emotionally } \\
\text { Incompetent } \\
(2)\end{array}$ & $\begin{array}{c}\text { Emotionally } \\
\text { Dissonant } \\
(3)\end{array}$ & $\begin{array}{l}\text { Low } \\
\text { Irony } \\
(4)\end{array}$ & $\begin{array}{c}\text { Emotionally } \\
\text { Unwilling } \\
\text { (5) }\end{array}$ & $\begin{array}{c}\text { ANOVA } \\
F \text {-Statistic }\end{array}$ \\
\hline \multicolumn{7}{|c|}{ Coping with envy } \\
\hline $\begin{array}{l}\text { Manage } \\
\text { experience }\end{array}$ & $4.58^{c}$ & 4.08 & 4.45 & 4.31 & 4.13 & $\begin{array}{c}2.67(d f=4 \\
p<0.05)\end{array}$ \\
\hline $\begin{array}{l}\text { Manage } \\
\text { expression }\end{array}$ & $5.82^{\mathrm{d}}$ & 5.45 & 5.35 & $5.91^{d}$ & 5.63 & $\begin{array}{c}3.58(d f=4 \\
p<0.01)\end{array}$ \\
\hline \multicolumn{7}{|c|}{ Relationship quality } \\
\hline (colleagues) & $\mathbf{5 . 0 6}^{\mathbf{a}}$ & 4.21 & 4.23 & $4.65^{b}$ & 4.00 & $\begin{array}{c}14.82(d f=4 \\
p<0.01)\end{array}$ \\
\hline \multicolumn{7}{|c|}{ Note: Values in this table are based on 7-point Likert scales. } \\
\hline \multicolumn{7}{|c|}{${ }^{a}$ Cluster is significantly higher than clusters $2,3,4$, and 5.} \\
\hline \multicolumn{7}{|c|}{${ }^{\mathrm{b}}$ Cluster is significantly higher than clusters 2,3 , and 5 . } \\
\hline \multicolumn{7}{|c|}{ ' Cluster is significantly higher than cluster 2.} \\
\hline
\end{tabular}

university degree) versus low education (lower than college degree), thus creating a dichotomous variable to be included in the analysis. The MANCOVA produced the following statistics: Wilks' lambda of $0.708, F=5.82, p<0.000$. This suggests that the dependent variables differ significantly across the five types of emotionally wise salespeople. Cluster membership explained 11 percent of the variance of coping strategies and 24 percent of the variance in relationship quality. The results of the analysis are summarized in Table 2.

Coping with Envy. The $F$-values show that membership in the EW clusters is associated with substantial differences in coping behaviors when experiencing envy. Table 2 demonstrates that salespeople belonging to the high-EW cluster achieve significantly higher scores on both strategies of coping with envy, that is, managing the experience of envy and managing the expression of envy. Salespeople high in EW are significantly better than less emotionally wise salespeople at regulating the experience of their envy. The salespeople high in EW use their envy as a source of self-motivation to work harder. In addition, salespeople high in EW, as well as salespeople belonging to the low-irony cluster, control their expressions of envy significantly more than individuals falling into the emotionally incompetent cluster or the emotionally dissonant cluster. $\mathrm{H} 3$ is thus mainly substantiated.

Relationship Quality. The $F$-value in Table 2 shows that the relationship between the five types of emotionally wise salespeople and quality of relationships with colleagues is substantial. Salespeople high in EW attain significantly better relationships with colleagues in their organization than all other salespeople. 
H4 is thus supported. Salespersons who belong to the low-irony cluster still achieve significantly better relationships with their colleagues than the emotionally incompetent, emotionally dissonant, and emotionally unwilling salespeople.

In sum, Study 1 provides evidence for the main theme of this study. That is, high $\mathrm{EW}$ is defined by the ability to integrate all dimensions of $\mathrm{EW}$, and this results in the attainment of better relationships with colleagues and better coping with envy. The other groups, defined by those salespeople with low EW on one or more dimensions, fared relatively worse, except for the low-irony group, which achieved relationship quality and coped at a level intermediate to the high-EW group and the other groups. These findings indicate that EW is configurational in nature, and its seven proficiencies are largely non-compensatory.

\section{STUDY 2: EMOTIONAL WISDOM AND RELATIONSHIPS WITH CUSTOMERS}

\section{Configurations of Emotional Wisdom}

After investigating configurations of EW for salespeople in an intra-organizational setting (i.e., with colleagues), configurations of salespeople's EW in an interorganizational setting (i.e., with customers) will now be examined. This is a conceptual replication and moreover extends the generalizability of the EW framework by applying it to an entirely different type of salesforce. It is predicted that within this domain salespeople also need to achieve EW so as to better cope with and regulate their emotions and also to enable them to achieve better relationships. In other words, salespersons in inter-organization contexts have to integrate the seven proficiencies of $\mathrm{EW}$ in their relationships with customers, such that seeming contradictions or conflicts between the proficiencies are harmonized. Each domain requires its own integration of apparent contradictions. For instance, salespeople in front of customers need to regulate their self-presentation yet demonstrate sincerity at the same time. Indeed, based on the extant literature on emotional work (e.g., Hochschild, 1983; Morris \& Feldman, 1996), it is expected that configurations of emotionally wise salespeople for the customer setting will be found similar to those for the intraorganizational work setting in Study 1. Hence,

H5: Salespeople will differ in emotional wisdom such that the pattern of responses to measures of the seven proficiencies will yield clusters of salespeople that reflect the theoretical themes developed and found in Study 1.

\section{Validation of the Configurations in an Inter-Organizational Setting}

Similar to Study 1, it is proposed that salespeople with high EW will have better relationships with their customers and cope more efficiently with potentially disruptive emotions than emotionally less wise salespeople.

Emotional Wisdom and Coping with Pride. Recent research indicates that pride is one of the most frequently and most intensely felt emotions among 
salespeople (e.g., Verbeke, Belschak, \& Bagozzi, 2004). Analogous to the selfregulation of envy by salespeople in collegial settings, two general coping strategies are proposed that salespeople use to self-regulate pride in customer-seller settings: managing the experience of pride and managing the expression of pride (see Campos, 1994; Folkman \& Lazarus, 1988; Saarni, 1997, 1999). When a salesperson succeeds by making new sales and exceeding expectations of management, it is important to manage one's felt experience of pride so as not to become selfsatisfied or complacent. A certain amount of pride is energizing, but too much pride can dampen one's motivation (Verbeke, Belschak, \& Bagozzi, 2004). Likewise, it is important to manage one's expression of pride so that it is not perceived by others as hubris; this means consciously suppressing excessive displays of pride so as to avoid offending others and to maintain a certain degree of civility and harmony with coworkers and customers (Verbeke, Belschak, \& Bagozzi, 2004). By implementing these coping strategies, salespeople reconcile their personal and social interests and work to foster organizational flourishing (Sternberg, 1998; Kunzman \& Baltes, 2003). For the same reasons as presented for coping with envy developed in Study 1, it is predicted that salespeople high versus low in EW will make greater use of both coping strategies when experiencing pride with their customers. That is, by better solving ambiguities and contradictions in one's emotions as they relate to their social environment, salespeople selfregulate the personal and interpersonal aspects of felt and expressed pride to advantage. Therefore, emotionally wise salespeople should cope better with their pride than less emotionally wise salespeople,

H6: Emotionally wise salespeople regulate the experience and the expression of felt pride more than less emotionally wise salespeople.

Emotional Wisdom and Customer Relations. Salespeople who receive information about competitors, the market, and their own organization from customers are said to have good customer relations. Customers appreciate salespeople who demonstrate EW by appearing to effectively take into account both customers' and sellers' interests (Szulanski, 1996; Crosby, Evans, \& Cowles, 1990). Maister and Galford (2000) term such an orientation on the part of salespeople "other-oriented customer contacts," and note that it builds trust. Trust, in turn, enhances the sharing of information (e.g., Szulanski, 1996). Emotional wisdom on the part of salespeople provides the personal and interpersonal basis for establishing high levels of trust and facilitates the sharing of information in terms of customer disclosure. Thus,

H7: Emotionally wise salespeople achieve higher customer disclosure than less emotionally wise salespeople.

\section{STUDY 2 METHOD}

\section{Sample}

To test the replicability and generalizability of EW and its effects, 780 questionnaires were sent to salespeople who worked in two automotive dealerships in the Netherlands. Two hundred twenty salespeople returned the questionnaires for a 
$28 \%$ response rate. In exchange for their participation, respondents received a gift worth about 12 U.S. dollars. The sample can be described as follows: a majority $(78 \%)$ of the salespeople were men, $34 \%$ of the salespeople were 30 years old and younger, $39 \%$ were between 30 and $40,13 \%$ between 41 and 50, and $14 \%$ were older than 50 . With respect to experience, $24 \%$ of the sample had been with the organization less than 2 years, $51 \%$ had been with the firm between 2 and 6 years, and $25 \%$ were with the company between 6 and 20 years. With regard to education, $72 \%$ had finished basic and vocational studies, while $28 \%$ had a university degree.

\section{Measures}

Emotional Wisdom. Consistent with Study 1, the same seven factors of EW were used, but were adapted to a customer setting (e.g., for empathy, "I can easily put myself in the place of the customers and their needs"). Further, because of time restrictions imposed by the sponsors, the scale was shortened to 17 items by using those items from Study 1 that achieved the highest factor loadings and choosing two to four items per scale. A list of the items per dimension with factor loadings and reliabilities is presented in the Appendix (see italicized items therein).

The coping with pride scale had ten 7-point Likert scale items. Item development was guided by existing research on coping (e.g., Folkman \& Lazarus, 1988) and coping strategies identified as most adaptive in the literature (Saarni, 1997, 1999). Five items concern salespeople's efforts to manage the experience of their pride (e.g., "I think: Remain the person you are," $\alpha=0.78$ ). Five items measure salespersons management of the expression of their pride (e.g., "I try not to show too much self-satisfaction so that I do not give the impression of being arrogant," $\alpha=0.87$ ).

Customer Disclosure. This scale consists of three items capturing the extent to which customers are willing to provide salespeople with information about competitors, the market, and their own organization and follows the theory developed by Nahapiet and Ghoshal (1998) and Crosby, Evans, and Cowles (1990) (e.g., "Customers easily share information about their organization with me," $\alpha=0.73)$.

\section{Confirmatory Factor Analysis}

To investigate the convergent and discriminative validity of the measures, a CFA was run, which provided the following results: $\chi^{2}(360)=556.56(p=0.00)$, $\mathrm{CFI}=0.91$, and RMSEA $=0.05$. Factor loadings were moderate to very high: empathy ( 0.60 to 0.71$)$, guilt ( 0.42 to 0.74$)$, authenticity ( 0.78 to 0.86$)$, self-presentation ( 0.74 to 0.84 ), helping others to accept one's emotions ( 0.59 to 0.78 ), irony ( 0.64 to 0.77$)$, character ( 0.64 to 0.79 ), social capital with customers $(0.61$ to $0.75)$, managing one's expression of pride (0.59 to 0.90$)$, and managing one's experience of pride ( 0.53 to 0.85$)$. The measures of discriminant validity reveal that the factors are distinct.

To test for common method variance, a same-source first-order factor was again added, which had the indicators of all the self-report measures loading on it (Podsakoff et al., 2003). Similar to Study 1, factor loadings and inter-factor correlations were not substantially influenced by common method variance. 
Table 3. Results of the Cluster Analysis in Study 2.

\begin{tabular}{lcccr}
\hline & $\begin{array}{c}\text { High } \\
\text { Emotional } \\
\text { Wisdom } \\
(n=34)\end{array}$ & $\begin{array}{c}\text { Emotionally } \\
\text { Incompetent } \\
(n=53)\end{array}$ & $\begin{array}{c}\text { Emotionally } \\
\text { Dissonant } \\
(n=61)\end{array}$ & $\begin{array}{c}\text { Low } \\
\text { Irony } \\
(n=68)\end{array}$ \\
\hline Self-presentation & 1.06 & -0.51 & 0.29 & 0.55 \\
Empathy & 0.80 & -0.54 & -0.29 & 0.27 \\
Irony & 1.33 & -0.74 & 0.40 & -0.44 \\
Authenticity & 0.83 & -1.70 & -0.46 & 0.22 \\
Guilt dissociation & 0.68 & -0.30 & -0.75 & 0.57 \\
Helping others & 1.14 & -0.80 & -0.16 & 0.20 \\
Character & 0.87 & -0.71 & 0.23 & -0.09 \\
\hline
\end{tabular}

Note: Values in this table are $z$-standardized; that is, values of about zero indicate an average activity on this dimension.

\section{STUDY 2 RESULTS}

\section{Cluster Analysis}

The same clustering approach was used for Study 2 as described in Study 1. The hierarchical cluster analysis indicated a plausible range of three to seven clusters. The kappas for the 3-, 4-, 5-, 6-, and 7-cluster solutions were $0.67,0.70$, $0.59,0.53$, and 0.64 , suggesting the 4 -cluster solution as the most internally valid combination of clusters. Results of the final cluster analysis are shown in Table 3.

The structure of the clusters found in Study 2 is very similar to the one in Study 1: Four of the five clusters found in Study 1 were replicated in Study 2. Cluster 1 represents salespeople with high EW (the high emotionally wise cluster). Individuals in this cluster score highest on all of the seven proficiencies of EW. In contrast, salespeople in cluster 2 (the emotionally incompetent cluster) score consistently lowest on all proficiencies, with the exception of guilt, where cluster 3 scores even lower. Cluster 3 comprises salespeople who are characterized by strong feelings of inauthenticity and guilt about the way they handle their emotions (the emotionally dissonant cluster). Even though they are able to use their emotions instrumentally toward customers, they are not very empathetic and are not well able to help customers to accept their genuine emotions. However, they make considerable use of an ironic outlook in their emotional work and apply moral norms. In sum, this group demonstrates key characteristics similar to those found in Study 1. Salespersons who fall in cluster 4 score moderately high on all the dimensions of EW except irony, where they score low, hence cluster 4 is termed the low-irony cluster. These people feel empathetic toward customers and are able to regulate their emotions instrumentally. At the same time, they are also able to help their customers to accept their genuine emotions, feel authentic about the way they handle their emotions, and are able to handle their guilt well. Yet individuals in this cluster are unable to distance themselves and regulate their emotions through the use of irony.

Study 1 provided evidence for five different groups of emotionally wise salespeople. In Study 2, four of these types were replicated (hence largely supporting 
H5). Both cluster analyses yielded similar results on the core characteristics defining the different clusters.

Why was a group of salespeople not found unwilling to regulate their emotions in Study 2? As pointed out in the literature, the ability and willingness of people to engage in emotional work depends on such situational and individual factors as clarity of display rules (Ashforth \& Tomiuk, 2000; Morris \& Feldman, 1996). One reason for finding a group of salespeople unwilling to regulate their emotions in Study 1 but not Study 2 might be found in the different focuses of the studies. Whereas in Study 1 an internal setting (i.e., interactions with colleagues) was investigated, emotional wisdom from an external perspective (i.e., with customers) was explored in Study 2. The display rules for internal settings are most likely vaguer and less scripted than for customer contacts. Moreover, customer contacts are the defining feature of salespeople's work. Contacts with colleagues in their own company, by contrast, might not be seen as the most important part of their work by some salespersons, and these salespersons may not see the need to take extra effort to engage in emotional work with their colleagues. Salespeople meet and interact with the same colleagues nearly every day. Managing one's relationships with other sales colleagues, therefore, may be difficult, as the contacts are frequent, intense, and of long duration, resulting in more psychological energy and physical effort required to engage in emotional work (Morris \& Feldman, 1996). Likewise, because salespeople have ongoing relationships with colleagues, they may avoid attempts at regulation because they do not wish to disturb whatever equilibrium exists. In still other instances, some salespeople may simply find regulating their emotions with colleagues unnecessary. On the other hand, given that salespeople are directly dependent on customers for their livelihood, they should be motivated to resolve any mismatches or misunderstandings concerning emotions because they need to satisfy customers' demands to make sales. All these possibilities are of course speculation, and more research is needed to understand why some salespeople are unwilling to regulate their emotions when dealing with colleagues.

\section{Validation: Results of MANCOVA}

As a validation of the configurations of emotional wisdom, the influence of cluster membership on customer disclosure and coping with pride was examined. A MANCOVA was run with customer disclosure and coping as dependent variables and the configurational EW clusters as multicategory independent treatment variables. Similar to Study 1, age, years of working experience, and education (as a dichotomous variable high $=$ college or university degree vs. low = lower than college degree) was included in the analysis.

The MANCOVA produced the following statistics: Wilks' lambda of 0.734 , $F=6.70, p<0.000$. This suggests that the dependent variables differ significantly across the four types of emotionally wise salespeople. Cluster membership explained 9 percent of the variance of coping strategies with pride and 22 percent of the variance for relationship quality with customers.

Coping with Pride. As the $F$-values in Table 4 show, membership in the EW cluster is associated with substantial differences in salespeople's coping behavior when experiencing pride. It can be seen that the emotionally wise salespeople achieve significantly higher scores on both strategies in coping with 


\begin{tabular}{|c|c|c|c|c|c|}
\hline & $\begin{array}{c}\text { High } \\
\text { Emotional } \\
\text { Wisdom } \\
\text { (1) }\end{array}$ & $\begin{array}{l}\text { Emotionally } \\
\text { Incompetent } \\
(2)\end{array}$ & $\begin{array}{c}\text { Emotionally } \\
\text { Dissonant } \\
(3)\end{array}$ & $\begin{array}{l}\text { Low } \\
\text { Irony } \\
(4)\end{array}$ & $\begin{array}{c}\text { ANOVA } \\
F \text {-Statistic } \\
(p<0.05)\end{array}$ \\
\hline \multicolumn{6}{|l|}{ Coping with pride } \\
\hline Manage experience & $5.83^{c}$ & 5.27 & 5.61 & 5.26 & $2.79(d f=3, p<0.04)$ \\
\hline Manage expression & $5.89^{\mathrm{a}}$ & 5.27 & 5.33 & 5.26 & $3.32(d f=3, p<0.05)$ \\
\hline $\begin{array}{l}\text { Customer disclosure } \\
\text { (customers) }\end{array}$ & $6.24^{a}$ & 5.20 & 5.22 & $\mathbf{5 . 6 5} \mathbf{b}^{\mathbf{b}}$ & $17.13(d f=3, p<0.02)$ \\
\hline \multicolumn{6}{|c|}{ Note: Values in this table are based on 7-point Likert scales. } \\
\hline \multicolumn{6}{|c|}{${ }^{\text {a }}$ Cluster is significantly different from clusters 2,3 , and 4.} \\
\hline \multicolumn{6}{|c|}{${ }^{\mathrm{b}}$ Cluster is significantly different from clusters 2 and 3.} \\
\hline
\end{tabular}

pride. That is, they are able to manage their expression of pride significantly more than salespeople in the other three clusters, and are significantly better able to manage their experience of pride so as to stay more focused than salespeople in two of the other three clusters.

Customer Disclosure. The $F$-values in Table 4 indicate that the relationship between membership in the EW clusters and customers' disclosure of knowledge is substantial. While the emotionally wise salespeople achieve significantly higher customer disclosure than salespeople in all the other three clusters, lowirony salespeople also attain significantly more information from their customers than salespersons falling into the emotionally incompetent and the emotionally dissonant clusters.

In sum, the data provide strong support for $\mathrm{H} 6$ and H7: Highly emotionally wise salespeople achieve significantly higher scores on coping and customer disclosure than their less emotionally wise colleagues. The results of the validation analyses of the configurations of EW in Studies 1 and 2 converge to a high degree.

\section{GENERAL DISCUSSION}

To date, the concept of EI has attracted a lot of attention, but many scholars neglect the potential negative social implications of displays of EI (see Barrett \& Gross, 2001; Kunzman \& Baltes, 2003). In line with earlier developments in the study of wisdom in psychology, this study developed measures and tested new hypotheses of the effects of EW in an inter- and intra-organizational context. In doing so, a configurational approach was employed to differentiate the high from less emotionally wise salespeople. In both studies, a distinct group of emotionally wise salespeople was found, based on scores on seven dimensions; these salespeople coped better with emotionally challenging situations and achieved better social relationships than other salespeople scoring lower on the dimensions. In this regard, EW might be considered a special case of the emerging 
frameworks found in positive psychology (see Baltes \& Staudinger, 2000) and positive organizational behavior (Luthans, 2002, 2003; Rousseau \& Fried, 1998), which seek to discover and build on those factors that foster the joint flourishing of individuals, communities, and societies. At the level of positive qualities of people, it helps to promote personal well-being in terms of adequate coping with emotions as well as performance by facilitating social relationships in the workplace.

The results of the two studies suggest that a configurational perspective on EW provides fresh insights for salesforce management and new avenues for research (e.g., Demerouti, Verbeke, \& Bakker, 2005). Emotionally wise salespeople are not so much quantitatively as qualitatively different from those who are less emotionally wise. That is, the seven dimensions of EW combine holistically to the extent that their full integration is required to lead to better coping and enhanced social relationships. The salespeople in the high emotionally wise cluster received consistently higher scores on all seven dimensions of EW, whereas salespeople in the other clusters not only scored lower on all dimensions than the high EW group, but also scored lowest on one or more of the seven dimensions. The literature on the regulation of emotions within organizations has also developed along configurational lines, for instance, by identifying different types of emotional workers (e.g., Ashforth \& Tomiuk, 2000; Rafaeli \& Sutton, 1987). Finally, configurational ideas can be found in management theory as well (in the form of typologies), as exemplified by the work of Kets de Vries (1999) or in the Myers-Briggs typology. Practitioners appreciate such typologies because they want to understand and predict the behavior of employees, and typologies provide broad policy guidelines.

Although the findings are consistent across the two studies, some limitations of the present research should be acknowledged. First, the findings are based on self-reported measures, which is an ongoing concern in behavioral research. In this regard, several researchers have argued that, depending on the research topic, self-report measures may be the most useful ones, in particular when trying to understand how people feel (e.g., Howard, 1994; Schmitt, 1994; Spector, 1994). In addition, meta-analyses on percept inflation indicate that the extent of inflation of the relationships between variables measured by means of selfreports may be overestimated (Crampton \& Wagner, 1994), and meta-analyses in the personal selling area suggest that subjective outcome measures are reliable and valid (Churchill et al., 1985).

Second, a cross-sectional design was used, which limits conclusions about causality. For instance, it is possible that salespeople infer at least partly their EW from the quality of their social relationships and success at coping with pride or envy. An experimental or longitudinal design would help to clarify questions about causality in this regard.

An interesting question for the future is whether EW can be fostered. Although Sternberg (1998) notes that wisdom is a product of learning, it remains to be shown that EW can be learned. And even if the individual dimensions of EW can be cultivated, it would seem to be a daunting task to shape these into a holistic configuration through training, coaching, and other managerial practices. Then, too, whether EW can be selected or taught, the question arises whether it can be lost and what can be done to sustain it. These important issues for the future suggest that intervention and longitudinal research will be needed to gain insights here (Bagozzi \& Nataraajan, 2000). 


\section{REFERENCES}

Adler, P. S., \& Kwon, S.-W. (2002). Social capital: Prospects for a new concept. Academy of Management Review, 27, 17-40.

Ashforth, B. E., \& Humphrey, R. H. (1993). Emotional labor in service roles: The influence of identity. Academy of Management Review, 18, 88-115.

Ashforth, B. E., \& Tomiuk, M. A. (2000). Emotional labour and authenticity: Views from service agents. In S. Fineman (Ed.), Emotion in organizations (pp. 184-203). London: Sage.

Averill, J. R. (1999). Individual differences in emotional creativity: Structure and correlates. Journal of Personality, 67, 331-371.

Avolio, B. J., Howell, J. M., \& Sosik, J. J. (1999). A funny thing on the way to the bottom line: Humor as a moderator of leadership style effects. Academy of Management Journal, 42, 219-227.

Bagozzi, R. P., \& Nataraajan, R. (2000). The year 2000: Looking forward. Psychology \& Marketing, 17, 1-11.

Bagozzi, R. P., Verbeke, W. J. M. I., Dietvorst, R. C., Belschak, F. D., Schraa-Tam, C. (2010). Looking into the minds of Machiavellian salespeople: Neural mechanisms behind instrumental action. Unpublished working paper, Ross School of Business, University of Michigan.

Baltes, P. B., \& Staudinger, U. M. (2000). A metaheuristic (pragmatic) to orchestrate mind and virtue toward excellence. American Psychologist, 55, 122-136.

Barrett, L. F., \& Gross, J. J. (2001). Emotional intelligence: A process model of emotion representation and regulation. In T. J. Mayne \& G. A. Bonanno (Eds.), Emotions: Current issues and future directions (pp. 286-310). New York: Guilford.

Barsade, S. G. (2002). The ripple effect: Emotional contagion and its influence on group behavior. Administrative Science Quarterly, 47, 644-675.

Bentler, P. (1990). Comparative fit indices in structural models. Psychological Bulletin, 107, 238-246.

Bigelow, J. (1992). Developing managerial wisdom. Journal of Management Inquiry, 1, 143-153.

Blau, P. M. (1964). Exchange and power in social life. New York: Wiley.

Brown, A. D., \& Starkey, K. (2000). Organizational identity and learning: A psychodynamic perspective. Academy of Management Review, 25, 102-120.

Browne, M. W., \& Cudeck, R. (1993). Alternative ways of assessing model fit. In K. A. Bollen \& J. S. Long (Eds.), Testing structural equation models (pp. 136-162). Newbury Park, CA: Sage.

Campos, J. (1994, Spring). The new functionalism in emotion. SRCD Newsletter, 1-15.

Cherniss, C., \& Goleman, D. (Eds.). (2001). The emotionally intelligent workplace. San Francisco: Jossey-Bass.

Christie, R., \& Geiss, F. L. (1970). Studies in Machiavellianism. New York: Academic Press.

Churchill, G. A., Ford, N. M., Hartley, S. W., \& Walker, O. C. (1985). The determinants of salesperson performance: A meta-analysis. Journal of Marketing Research, 22, 103-118.

Clark, M. S., \& Mills, J. (1979). Interpersonal attraction in exchange and communal relationships. Journal of Personality and Social Psychology, 37, 12-24.

Clark, M. S., Mills, J., \& Powell, M. C. (1986). Keeping track of needs in communal and exchange relationships. Journal of Personality and Social Psychology, 51, 333-338.

Crampton, S. M., \& Wagner, J. A. (1994). Percept-percept inflation in microorganizational research: An investigation of prevalence and effect. Journal of Applied Psychology, 79, 67-76.

Crosby, L. A., Evans, K. R., \& Cowles, D. (1990). Relationship quality in services selling: An interpersonal influence perspective. Journal of Marketing, 54, 68-81.

Demerouti, E., Verbeke, W., \& Bakker, A. B. (2005). Exploring the relationship between a multidimensional and multifaceted burnout concept and self-rated performance. Journal of Management, 31, 186-209. 
Deutsch, M. (1968). Field theory. In G. Lindsay \& E. Aronson (Eds.), Handbook of social psychology, Vol. 1 (pp. 412-487). Reading, MA: Addison-Wesley.

Dixon, N. F. (1980). Humor: A cognitive alternative to stress? In I. G. Sarason \& C. D. Spielberger (Eds.), Stress and anxiety, Vol. 7 (pp. 281-289). Washington, DC: Hemisphere.

East, M. P., \& Watts, F. N. (1999). Jealousy and envy. In T. Dalgleish \& M. Power (Eds.), Handbook of cognition and emotion (pp. 569-590). Chichester: John Wiley \& Sons.

Eisenberg, N. (2000). Empathy and sympathy. In M. Lewis, \& J. M. Haviland-Jones (Eds.), Handbook of emotions, 2nd ed. (pp. 677-691). New York/London: Guilford.

Emmons, R. A. (1999). The psychology of ultimate concerns: Motivation and spirituality in personality. New York: Guilford.

Erickson, R. J. (1997). Putting emotions to work (or, coming to terms with a contradiction in terms). In R. J. Erickson \& B. Cuthbertson-Johnson (Eds.), Social perspectives on emotion, Vol. 4 (pp. 3-18). Greenwich, CT: JAI Inc.

Erikson, E. (1968). Identity, youth, and crisis. New York: Norton.

Farmer, S. M., \& Maslyn, J. M. (1999). Why are styles of upward influence neglected? Making the case for a configurational approach to influence. Journal of Management, $25,653-689$.

Festinger, L. (1957). A theory of cognitive dissonance. Palo Alto, CA: Stanford University.

Fineman, S. (2000). Emotion in organizations, 2nd ed. London: Sage.

Folkman, S., \& Lazarus, R. S. (1988). Coping as a mediator of emotions. Journal of Personality and Social Psychology, 54, 466-475.

Fredrickson, B. L. (2001). The role of positive emotions in positive psychology: The broadenand-build theory of positive emotions. American Psychologist, 56, 218-226.

Goleman, D. (1998). Working with emotional intelligence. New York: Bantam Books.

Hardin, R. (2003). Gaming trust. In E. J. Ostrom \& J. Walker (Eds.), Trust and reciprocity (pp. 80-101). New York: Russell Sage.

Harter, S. (2002). Authenticity. In C. R. Snyder \& S. J. Lopez (Eds.), Handbook of positive psychology (pp. 382-394). London: Oxford University.

Hatch, M. (1997). Irony and the social construction of contradiction in the humor of a management team. Organization Science, 8, 275-288.

Haviland, M. G., \& Reise, S. P. (1996). A California Q-set alexithymia prototype and its relationship with ego-control and ego-resiliency. Journal of Psychosomatic Research, 41, 597-608.

Hochschild, A. R. (1983). The managed heart. Berkeley: University of California.

Holmes, J. G., \& Rempel, J. K. (1989). Trust in close relationships. In C. Hendrick (Ed.), Close relationships (pp. 187-220). Newbury Park, CA: Sage.

Homburg, C., Workman, J. P., \& Jensen, O. (2002). A configural perspective on key account management. Journal of Marketing, 66, 38-51.

Howard, G. S. (1994). Why do people say nasty things about self-reports? Journal of Organizational Behavior, 15, 399-404.

Huy, Q. N. (1999). Emotional capability, emotional intelligence, and radical change. Academy of Management Review, 24, 325-345.

Huy, Q. N. (2002). Emotional balancing of organizational continuity and radical change: The contribution of middle managers. Administrative Science Quarterly, 47, 31-69.

Keltner, D. (1995). The signs of appeasement: Evidence for the distinct displays of embarrassment, amusement, and shame. Journal of Personality and Social Psychology, 68, 441-454.

Keltner, D., \& Bonanno, G. A. (1997). A study of laughter and dissociation: Distinct correlates of laughter and smiling during bereavement. Journal of Personality and Social Psychology, 73, 687-702.

Kets de Vries, M. F. R. (1999). What's playing in the organizational theater? Collusive relationships in management. Human Relations, 52, 745-773.

Kipnis, D., \& Schmidt, S. M. (1988). Upward-influence styles: Relationship with performance evaluations, salary, and stress. Administrative Science Quarterly, 33, $528-542$. 
Kunzmann, U., \& Baltes, P. B. (2003). Beyond the traditional scope of intelligence: Wisdom in action. In R. J. Sternberg, J. Lautrey, \& T. I. Lubart (Eds.), Models of intelligence: International perspectives (pp. 329-343). Washington, DC: APA.

Leary, M. R., \& Kowalski, R. M. (1990). Impression management: A literature review and two-component model. Psychological Bulletin, 107, 34-47.

Lewicki, R. J., McAllister, D. J., \& Bies, R. J. (1998). Trust and distrust: New relationships and realities. Academy of Management Review, 23, 438-458.

Luthans, F. (2002). Positive organizational behavior: Developing and managing psychological strengths. Academy of Management Executive, 16, 57-75.

Luthans, F. (2003). Positive organizational behavior: An idea whose time has truly come. Journal of Organizational Behavior, 24, 437-442.

Maister, D., \& Galford, R. (2000). The trusted advisor. New York: Free Press.

Mayer, J. D., Salovey, P., \& Caruso, D. R. (2000). Emotional intelligence. In R. J. Sternberg (Ed.), Handbook of intelligence, 2nd ed. (pp. 396-421). New York: Cambridge University Press.

Mayer, R. C., Davis, J. H., \& Schoorman, F. D. (1995). An interactive model of organizational trust. Academy of Management Review, 20, 709-734.

McAllister, D. J. (1995). Affect- and cognition-based trust as foundations for interpersonal cooperation in organizations. Academy of Management Journal, 38, 24-59.

Mehrabian, A., \& Epstein, N. (1970). A measure of emotional empathy. Journal of Personality, 40, 525-543.

Meyer, A. D., Tsui, A. S., \& Hinings, C. R. (1993). Configurational approaches to organizational analysis. Academy of Management Journal, 36, 1175-1195.

Morgan, R. M., \& Hunt, S. D. (1994). The commitment-trust theory of relationship marketing. Journal of Marketing, 58, 20-38.

Morris, J. A., \& Feldman, D. C. (1996). The dimensions, antecedents, and consequences of emotional labor. Academy of Management Review, 21, 986-1010.

Mumby, D. K., \& Putnam, L. L. (1992). The politics of emotion: A feminist reading of bounded rationality. Academy of Management Review, 17, 465-486.

Nahapiet, J., \& Ghoshal, S. (1998). Social capital, intellectual capital, and the organizational advantage. Academy of Management Review, 23, 242-266.

Parkinson, B. (1991). Emotional stylists: Strategies of expressive management among trainee hairdressers. Cognition and Emotion, 5, 419-434.

Pascual-Leone, J. (1990). An essay on wisdom: Toward organismic processes that make it possible. In R. J. Sternberg (Ed.), Wisdom (pp. 244-278). Cambridge: Cambridge University.

Podsakoff, P. M., \& Organ, D. W. (1986). Self-reports in organizational research: Problems and prospects. Journal of Management, 12, 69-82.

Podsakoff, P. M., MacKenzie, S. B., Podsakoff, N. P., \& Lee, J.-Y. (2003). Common method bias in behavioral research: A critical review of the literature and recommended remedies. Journal of Applied Psychology, 88, 879-903.

Preston, S. D., \& de Waal, F. B. M. (2002). Empathy: Its ultimate and proximate bases. Behavioral and Brain Sciences, 25, 1-72.

Punj, G., \& Stewart, D. (1983). Cluster analysis in marketing research: Review and suggestions for application. Journal of Marketing Research, 20, 134-148.

Rafaeli, A., \& Sutton, R. I. (1987). Expression of emotion as part of the work role. Academy of Management Review, 12, 23-37.

Rich, P. (1992). The organizational taxonomy: Definition and design. Academy of Management Review, 17, 758-781.

Rousseau, D. M., \& Fried, Y. (1998). Letter from the editors. Journal of Organizational Behavior, 19, 431-433.

Saarni, C. (1997). Coping with aversive feelings. Motivation and Emotion, 21, 45-63.

Saarni, C. (1999). The development of emotional competence. New York: Guilford.

Saarni, C. (2000). Emotional competence. A developmental perspective. In R. Bar-On \& J. D. A. Parker (Eds.), The handbook of emotional intelligence (pp. 68-91). San Francisco: Jossey-Bass. 
Salovey, P., \& Mayer, J. D. (1990). Emotional intelligence. Imagination, Cognition, and Personality, 9, 185-211.

Salovey, P., \& Pizarro, D. A. (2003). The value of emotional intelligence. In R. J. Sternberg, J. Lautrey, \& T. I. Lubart (Eds.), Models of intelligence: International perspectives (pp. 263-278). Washington, DC: APA.

Schmitt, N. (1994). Method bias: The importance of theory and measurement. Journal of Organizational Behavior, 15, 393-398.

Schutte, N. S., Malouff, J. M., Hall, L. E., Haggerty, D. J., Cooper, J. T., Golden, C. J., \& Dornheim, L. (1998). Development and validation of a measure of emotional intelligence. Personality and Individual Differences, 25, 167-177.

Seibert, S. E., Kraimer, M. L., \& Liden, R. C. (2001). A social capital theory of career success. Academy of Management Journal, 44, 219-237.

Seligman, M. E. P., \& Csikszentmihalyi, M. (2000). Positive psychology: An introduction. American Psychologist, 55, 5-14.

Sifneos, P. E. (1973). The prevalence of "alexithymic" characteristics in psychosomatic patients. Psychotherapy and Psychosomatics, 22, 225-262.

Singh, J. (1990). A typology of consumer dissatisfaction response styles. Journal of Retailing, 66, 57-99.

Spector, P. E. (1994). Using self-report questionnaires in OB research: A comment on the use of a controversial method. Journal of Organizational Behavior, 15, 385-392.

Staudinger, U. M., \& Baltes, P. B. (1996). Interactive minds: A facilitative setting for wisdomrelated performance? Journal of Personality and Social Psychology, 71, 746-762.

Sternberg, R. J. (1998). A balance theory of wisdom. Review of General Psychology, 2, 347-365.

Sternberg, R. J. (2003). Wisdom, intelligence, and creativity synthesized. Cambridge: Cambridge University.

Sternberg, R. J., Lautrey, J., \& Lubart, T. I. (2003). Where are we in the field of intelligence, how did we get there, and where are we going? In R. J. Sternberg, J. Lautrey, \& T. I. Lubart (Eds.), Models of intelligence: International perspectives (pp. 3-25). Washington, DC: APA.

Sutton, R.I. (1991). Maintaining norms about expressed emotions: The case of bill collectors. Administrative Science Quarterly, 36, 245-268.

Szulanski, G. (1996). Exploring internal stickiness: Impediments to the transfer of best practice within the firm. Strategic Management Journal, 17, 27-43.

Verbeke, W., Belschak, F., Bagozzi, R. P. (2004). The adaptive consequences of pride in personal selling. Journal of the Academy of Marketing Science, 32, 386-402.

Waters, J. (1980). Managerial skill development. Academy of Management Review, 5, 449-453.

Weick, K. E. (1993). The collapse of sensemaking in organizations: The Mann Gulch disaster. Administrative Science Quarterly, 38, 628-652.

Weitz, B., \& Bradford, K. D. (1999). Personal selling and sales management: A relationship marketing perspective. Journal of the Academy of Marketing Science, 27, 241-254.

Westwood, R. (2004). Comic relief: Subversion and catharsis in organizational comedic theatre. Organization Studies, 25, 775-795.

Wong, C.-S., \& Law, K. S. (2002). The effects of leader and follower emotional intelligence on performance and attitude. Leadership Quarterly, 13, 243-274.

Workman, J. P., Homburg, C., \& Jensen, O. (2003). Intraorganizational determinants of key account management effectiveness. Journal of the Academy of Marketing Science, $31,3-21$.

Zahn-Waxler, C., \& Robinson, J. (1995). Empathy and guilt: Early origins of feelings of responsibility. In J. P. Tangney \& K. W. Fischer (Eds.), Self-conscious emotions (pp. 143-173). New York: Guilford.

The ordering of author names is alphabetical. Correspondence regarding this article should be sent to: Richard Bagozzi, Ross School of Business and Department of Social and Administrative Sciences, College of Pharmacy, University of Michigan, Ann Arbor, MI 48109-1234 (bagozzi@umich.edu). 


\section{APPENDIX}

\section{Emotional Wisdom}

(Reliabilities and factor loadings in parentheses; Study 2 in italics.)

Empathy $(\alpha=0.77 / r=0.51)$

1. I can easily put myself in the place of my colleagues (customers) and their needs. (0.75/0.62)

2. I can tune my emotions to those of my colleagues (customers). (0.70/0.70)

3. I can easily sense the feelings of my colleagues. (0.59)

4. I can easily imagine how the choice of my words affects people's emotions. (0.70)

Guilt $(r=0.45 / 0.45)$

5. I feel little or no guilt about the way I manage my emotions. (0.45/0.42)

6. I feel little guilt when showing my enthusiasm during a conversation with colleagues (customers). (0.90/0.74)

Authenticity $(r=0.62 / 0.71)$

7. I feel that my expressed emotions are part of my sincere and deeper self. $(0.78 / 0.87)$

8. My expressed emotions are part of what I see as my truthful way of dealing with people. $(0.76 / 0.78)$

Self-presentation $(\alpha=0.82 / r=0.67)$

9. I am knowledgeable about how to create emotions to facilitate the way sales interactions operate. $(0.80 / 0.84)$

10. I can easily show a variety of emotions when the situation asks for it. $(0.80 / 0.74)$

11. I use my emotions strategically to facilitate interactions with colleagues. (0.68)

12. I can manage the expression of my emotions in front of colleagues during meetings. (0.67)

Helping others accept one's emotions $(\alpha=0.70 / 0.76)$

13. Others have learned to accept the way I manage my emotions. (0.56/0.58)

14. People accept how I manage my emotions. (0.60/0.78)

15. I feel that colleagues (customers) can quickly feel my emotions. (0.76/0.78) 
Irony $(\alpha=0.75 / 0.78)$

16. Laughing about myself takes care that I do not get too emotional with colleagues (customers). (0.61/0.73)

17. Laughing keeps me from worrying about the question whether I show emotions that are adequate for the given social context. (0.70/0.64)

18. Whatever happens, I have learned to accept my emotions and look at them with some irony. $(0.65 / 0.74)$

19. I can easily laugh about myself when my emotions get carried away. $(0.69 / 0.76)$

Character $(\alpha=0.70 / r=0.64)$

20. Although being flexible with my emotions I also have limits. (0.60/0.65)

21. I have norms about the way I manage my emotions with colleagues (customers). (0.68/0.79)

22. I have a clear idea to what extent I am willing to compromise my emotions. (0.54)

23. When colleagues make me express emotions that do not fit my norms and values, I show my disagreement. (0.45) 